\title{
A novel approach for preventing recurrence of malign pleural effusion: early phase pleurodesis
}

\author{
Ufuk Cobanoglu ${ }^{1}$, Ozgur Kemik², Sebahattin Celik ${ }^{3}$, Fuat Sayir ${ }^{1}$
}

1Department of Thoracic Surgery, University of Yuzuncu Yil, Van, Turkey
2Department of Surgical Oncology, University of Yuzuncu Yil, Van, Turkey
${ }^{3}$ Department of General Surgery, University of Yuzuncu Yil, Van, Turkey

Submitted: 18 August 2017

Accepted: 28 November 2017

Arch Med Sci 2018; 14, 6: 1404-1415

DOI: https://doi.org/10.5114/aoms.2017.72543

Copyright @ 2017 Termedia \& Banach

\section{Abstract}

Introduction: The effective control of malignant pleural effusion (MPE) is of paramount importance in the treatment of patients with disseminated cancer. In this study, we compared two different approaches (early pleurodesis versus late pleurodesis) to MPE.

Material and methods: Patients (188 cases) whose primary tumor type was known and who were confirmed to have MPE, were included in the study and were separated into two groups. One group consisted of patients who were asymptomatic and who underwent early phase pleurodesis (group I, $n=79$ ). The other group (group II, $n=109$ ) was composed of patients who were symptomatic and whose pleurodesis was performed later. In all cases, pleural effusion was evaluated by means of direct radiography. Computed tomography was performed with the goal of confirming the parenchymal or mediastinal lesions accompanying the pleural fluid.

Results: The rate of complete success in group I cases was observed to be higher, while the rate of recurrence was lower $(p=0.001$ and $p=0.002$, respectively) than group II. In multiple logistic regression analysis, co-morbidities and the group that patient belong were found to be significant in terms of pleurodesis success ( $p=0.02$ and $p=0.03$ ). There was a significant difference in survival time between group I and group II, with group I exhibiting longer average survival time (log rank test $p<0.001$ ).

Conclusions: We observed that the success rate was lower and the rate of recurrence higher in the late pleurodesis group, whose members already had greater volumes of pleural effusion.

Key words: malignant, pleural effusion, pleurodesis, recurrence.

\section{Introduction}

Malignant pleural effusion (MPE) occurs synchronously with the primary malignancy or may appear as a recurrence following treatment of the primary tumor [1].

Effusions with known tumor types where patients are symptomatic can be monitored. However, intervention is necessary during follow-up in a great many of these cases when the patients become symptomatic [2]. In these patients, the main objective is to eliminate symptoms such as labored breathing, coughing, and chest pain, and to improve quality of life by preventing recurrence of pleural effusion [3].

With these objectives in mind, methods which ensure obliteration of the pleural cavity following drainage of pleural fluid are employed.
Corresponding author: Prof. Ufuk Cobanoglu Department of Thoracic Surgery University of Yuzuncu Yil 65200 Van, Turkey Phone: +90 5362199397 E-mail: drucobanoglu@ hotmail.com 
Pleurectomy or pleural abrasion with chemical pleurodesis, thoracoscopy, and thoracotomy are all methods used to prevent recurrence of MPE [3].

In this study, pleurodesis was performed in early stage cases, where the primary tumor type was known and there were no symptoms related to the accumulation of pleural fluid, and in cases presenting with symptoms due to increased amounts of pleural fluid. The success and recurrence rates were compared with regard to the two groups as well as method of pleurodesis, and mean survival was determined.

\section{Material and methods}

In the period 2012-2016, 316 patients who had received follow-up care and treatment during consultation with our Medical Oncology, Respiratory Diseases, and Surgical Oncology clinics were confirmed to have MPE. Of these, 128 (40.51\%) cases were excluded from the study. Of those excluded, $12(9.37 \%)$ cases were in poor overall condition and were not expected to live long, were patients in the terminal stage, and/or had undergone intervention with only thoracentesis. A total of 17 (13.28\%) cases were patients who had undergone thoracotomy and/or thoracoscopic surgery via pleurectomy and/or decortication, it having been decided that chemical pleurodesis would not be effective due to expansion of the lungs. The other $99(77.35 \%)$ cases were patients where recurrence occurred despite earlier thoracentesis, pleural fluid drainage having been performed by tube thoracostomy and a PleurX silicon catheter. Of these, $37(37.37 \%)$ patients underwent pleurectomy or pleural abrasion following recurrence, while in $62(62.63 \%)$ cases, tube thoracostomy or thoracoscopy with pleurodesis was performed.

The remaining 188 (59.49\%) cases, whose primary tumor type was known and who were confirmed to have MPE, were included in the study and were separated into two groups.

While malignant cells were confirmed by pleural fluid cytology, closed pleural biopsy, and thoracoscopic biopsy in $53.73 \%$ of the cases, in $46.27 \%$ of malignant cells were not confirmed in the pleural fluid and pleural biopsies, despite the existence of a primary tumor. In these cases, a symptomatic period exceeding 1 month, absence of fever, and sanguineous pleural fluid $\left(70.000 \pm 40.000 \mathrm{~mm}^{3}\right)$ were established as diagnostic criteria for MPE. The pleural fluid that accumulated in these cases was evaluated as paramalignant effusion.

In all cases, pleural effusion was evaluated by means of direct radiography. Computed tomography (CT) was performed with the goal of confirming the parenchymal or mediastinal lesions accompanying the pleural fluid.

Group I consisted of cases with low levels of pleural fluid and no symptoms related to the buildup of pleural fluid that underwent pleurodesis in the early stage. Group II was composed of cases that had developed symptoms related to the buildup of pleural fluid (pleuritic pain, dry cough, and respiratory distress) with excessive amounts of plural effusion. The mean amount of pleural effusions in group I cases was $412.307 \pm 127.591$, and in group II cases was $2325.229 \pm 870.760$.

In group I patients, who had low levels of pleural fluid buildup, blunting in the costophrenic sinuses was confirmed in the posterior-anterior (PA) and standard lateral lung radiographs. In group II patients, who had high levels of pleural fluid buildup, following obtundation of the costophrenic sinuses and obliteration of the contour of the diaphragm, signs of concave homogeneous density and pushing against the mediastinum were detected.

Because simultaneous administration of bilateral pleural effusions may increase the risk of pulmonary edema, pleurodesis was first performed on the side containing more fluid.

Talc was employed as the sclerosing agent for pleurodesis in all cases. While an approximately $4 \mathrm{~g}$ dose of talc was administered by means of insufflation through video thoracoscopy, $2.5 \mathrm{~g}$ mixed with $250 \mathrm{ml}$ of physiological saline solution was applied through a chest tube or PleurX catheter.

In cases where talc pleurodesis was administered by chest tube and PleurX silicon, the tube was held closed for up to $1 \mathrm{~h}$ during dispersal of the sclerosing agent to the entire pleural surface. Pleurodesis was performed via video thoracoscopy in patients deemed unsuitable for radical surgery who could however undergo general anesthesia. In those cases, the procedure was performed under general anesthesia with single lung ventilation. Utilizing a single-use gas-propelled atomizer, the insufflation containing talc was distributed evenly over the pleural surface. The amount of fluid coming from the chest tube was recorded daily for all patients, and the tube was withdrawn when the daily volume of fluid fell below $100 \mathrm{ml}$.

Complications developing from pleurodesis were determined for cases in groups I and II. Patients were monitored monthly for 3 months following pleurodesis, and then every 3 months after that. At the end of the third month, the outcome for patients where no fluid was observed was considered completely successful. The outcomes of those whose PA lung radiographs or tomographs showed only localized fluid were classified as partially successful, and patients who experienced a relapse, as indicated by the excess accumulation of effusion, were considered to have an unsuccessful outcome.

In this study, pleurodesis was performed at an early stage in group I patients who had low amounts of pleural fluid, and at a later stage in 
group II patients who had excess amounts of pleural fluid. Success rates, involving the obliteration of the pleural space, and recurrence rates of pleural fluid buildup were determined separately, both with respect to the two groups and the method of pleurodesis applied. Mean survival was also assessed.

\section{Statistical analysis}

In comparing the success and recurrence rates in patients with malignant pleural effusions by group and method of pleurodesis performed, descriptive statistics for the characteristics under investigation are expressed as number and percentage. A Z-test and Fisher's definite probability test were used in comparisons of the data. A statistical significance level of $5 \%$ was chosen, and for calculations the MINITAB statistical package program was used.

Statistical analysis was performed using IBM SPSS (Armonk, NY, USA). Consistent factors were exhibited as mean \pm standard deviation or median (interquartile range), and analyzed using the Mann-Whitney $U$ test as appropriate. All out factors were displayed as recurrence (percentage) and analyzed using the $\chi^{2}$ test or Fisher's correct test as appropriate. Multiple logistic regression analysis was used to determine independent predictors of success with forward logistic regression to model independent predictors. Cumulative probability of survival time was estimated with Kaplan-Meier curves. Covariates with $p<0.05$ from univariate analysis were included in the multivariate analysis. All statistical tests were two-sided and $p<0.05$ was considered statistically significant.

\section{Results}

A full list of patient characteristics is given in Table I.

Of the study participants, 79 (42.02\%) were in group I and 109 (57.98\%) were in group II. In both groups the number of male patients was greater than that of female patients, while their average ages were similar. The most frequent cause of MPE in group I was lymphoma (34.2\%), whereas in group II it was non-small cell lung cancer $(41.28 \%)$ (Table I). Regarding the method of pleurodesis performed, the most common was the PleurX silicon catheter for group I and tube thoracostomy for group II (Table I). The most frequent complication associated with pleurodesis for both groups was determined to be fever (15/188; 7.97\%) (Table I).

Comparison of the recurrence and success rates of the two groups revealed a statistically significant difference in complete success $(p=0.002)$ and in recurrence following pleurodesis $(p=0.001)$ (Table II). According to these findings, the rate of complete success in group I cases was observed to be higher, while the rate of recurrence was lower.

No statistically significant difference was found between the method of pleurodesis used in group I cases and success and recurrence rates (Table III).

When success and recurrence rates for group II cases were compared with respect to pleurodesis methods, the difference in complete success rates between patients undergoing tube thoracostomy and PleurX catheter placement $(p=0.018)$ and in recurrence rates following pleurodesis ( $p$ $=0.024$ ) were statistically significant. A statistically significant difference in partial success rates was observed between patients undergoing tube thoracostomy and those undergoing thoracoscopy $(p=0.021)$ and PleurX catheter placement $(p=0.018)$ (Table IV).

The pleurodesis methods themselves were compared in terms of the success and recurrence rates for each group. Of the pleurodesis methods, tube thoracostomy and thoracoscopy were shown to have no statistically significant difference between the two groups with respect to success and recurrence rates. In assessing pleural catheterization, a statistically significant difference was observed between the two groups in terms of complete success and partial success and recurrence $(p=0.001)$ (Table V).

\section{Multiple logistic regression}

The success of the treatments administered to the 188 patients who participated in this study is expressed in three different ways. Pleurodesis was considered successful in patients who had no fluid at the end of the third month, while PA was considered partially successful in patients with localized fluid and unsuccessful in those with a recurrence of buildup of excess effusion, as shown by chest X-ray or tomography. A statistical comparison of the success rates of the two groups according to the treatment method applied is given in Tables II-V.

With the goal of evaluating both groups, a multiple logistic regression model was then established to examine the relationship between patient characteristics and pleurodesis success. The results of the multiple logistic regression, in which the two groups are jointly assessed, are presented in Table VI.

When the model fitting information established for multiple regression was examined for all patients, it was found to be compatible ( $p=$ $0.00013) . R^{2}$, calculated according to the pseudo $r^{2}$ values model, summarizes the proportion of variance in the dependent variable associated with the predictor (independent) variables. When the Nagelkerke [4] $r^{2}$ value is 0.8661 , it indicates that the model has high explanatory power. 
Table I. Demographics and other characteristics of each group

\begin{tabular}{|c|c|c|c|c|}
\hline \multirow[t]{2}{*}{ Parameter } & \multicolumn{2}{|c|}{ Group I } & \multicolumn{2}{|c|}{ Group II } \\
\hline & Values & $P$-value & Values & $P$-value \\
\hline Number of patients & $79(42.02 \%)$ & & 109 (57.98\%) & \\
\hline Age, mean \pm SE & $65 \pm 9.3$ & 0.15 & $72 \pm 11.4$ & 0.70 \\
\hline \multicolumn{5}{|l|}{ Gender: } \\
\hline Female & $33 / 79$ (41.77\%) & 0.31 & $38 / 109$ (38.86\%) & 0.87 \\
\hline Male & $46 / 79(58.23 \%)$ & & $71 / 109(65.14 \%)$ & \\
\hline \multicolumn{5}{|l|}{ Pathology causing MPE: } \\
\hline Lung (NSCLC) & $19(24.05 \%)$ & 0.000003 & $45(41.28 \%)$ & 0.07 \\
\hline Lung (SCLC) & $12(15.18 \%)$ & & $8(7.33 \%)$ & \\
\hline Breast cancer & $16(20.25 \%)$ & & $11(10.09 \%)$ & \\
\hline Larynx cancer & & & $3(2.75 \%)$ & \\
\hline Lymphoma & $27(34.2 \%)$ & & $7(6.43 \%)$ & \\
\hline Ovarian cancer metastasis & $2(2.53 \%)$ & & $4(3.67 \%)$ & \\
\hline Prostate cancer & & & $3(2.76 \%)$ & \\
\hline Stomach cancer & $3(3.79 \%)$ & & $14(12.85 \%)$ & \\
\hline Esophageal cancer & & & $11(10.09 \%)$ & \\
\hline Malignant fibrous histiocytoma & & & $1(0.91 \%)$ & \\
\hline Pancreatic cancer & & & $2(1.84 \%)$ & \\
\hline \multicolumn{5}{|l|}{ Method of pleurodesis: } \\
\hline Tubal thoracostomy & $21(26.58 \%)$ & 0.25 & $80(73.40 \%)$ & 0.14 \\
\hline Thoracoscopy & $9(11.40 \%)$ & & $11(10.09 \%)$ & \\
\hline PleurX silicon catheter & $49(62.02 \%)$ & & $18(16.51 \%)$ & \\
\hline \multicolumn{5}{|l|}{ Side effects of pleurodesis: } \\
\hline Fever & $6(7.59 \%)$ & 0.46 & $9(8.41 \%)$ & 0.57 \\
\hline Chest pain & $4(5.06 \%)$ & & $6(5.50 \%)$ & \\
\hline Atelectasis & & & $5(4.58 \%)$ & \\
\hline \multicolumn{5}{|l|}{ Stage of cancer: } \\
\hline First stage & $7(8.86 \%)$ & 0.19 & $0(0.00 \%)$ & 0.02 \\
\hline Second stage & $26(32.91 \%)$ & & $1(0.01 \%)$ & \\
\hline Third stage & $8(10.139 \%)$ & & $15(0.14 \%)$ & \\
\hline Fourth stage & $38(48.10 \%)$ & & $93(85 \%)$ & \\
\hline
\end{tabular}

NSCLC - non-small cell lung cancer, SCLC - small cell lung cancer.

When the regression data were analyzed, success in preventing the re-accumulation of pleural fluid following pleurodesis for both groups was shown to be affected by the presence of disease accompanying the cancer. Patient age, one of the parameters investigated with respect to its effects on success, was found to be slightly higher than the significance value at the 0.05 level (0.1016), and had
Table II. Comparison of group I and group II recurrence and success rates

\begin{tabular}{|lccc|}
\hline Variable & $\begin{array}{c}\text { Group I } \\
(n=79)\end{array}$ & $\begin{array}{c}\text { Group II } \\
(n=109)\end{array}$ & $P$-value \\
\hline Complete success & 47 & 41 & 0.002 \\
\hline Partial success & 21 & 29 & 0.997 \\
\hline Recurrence & 11 & 39 & 0.001 \\
\hline
\end{tabular}


Table III. Comparison of pleurodesis methods used in group I patients

\begin{tabular}{|lcccccc|}
\hline Variable & $\begin{array}{c}\text { Tube thoracostomy } \\
(n=21)(\mathrm{A})\end{array}$ & $\begin{array}{c}\text { Thoracoscopy } \\
(n=9)(\mathrm{B})\end{array}$ & $\begin{array}{c}\text { PleurX catheter } \\
(n=49)(\mathrm{C})\end{array}$ & $\begin{array}{c}\boldsymbol{P} \text {-value } \\
(\mathrm{A}-\mathrm{B})\end{array}$ & $\begin{array}{c}\boldsymbol{P} \text {-value } \\
(\mathrm{A}-\mathrm{C})\end{array}$ & $\begin{array}{c}\boldsymbol{P} \text {-value } \\
(\mathrm{B}-\mathrm{C})\end{array}$ \\
\hline Complete success & 9 & 5 & 33 & 0.521 & 0.054 & 0.509 \\
\hline Partial success & 7 & 3 & 11 & 0.999 & 0.360 & 0.517 \\
\hline Recurrence & 5 & 1 & 5 & 0.365 & 0.184 & 0.935 \\
\hline
\end{tabular}

Table IV. Comparison of pleurodesis methods used in group II patients

\begin{tabular}{|lcccccc|}
\hline Variable & $\begin{array}{c}\text { Tube thoracostomy } \\
(n=80)(A)\end{array}$ & $\begin{array}{c}\text { Thoracoscopy } \\
(n=11)(B)\end{array}$ & $\begin{array}{c}\text { PleurX catheter } \\
(n=18)(C)\end{array}$ & $\begin{array}{c}P \text {-value } \\
(\mathrm{A}-\mathrm{B})\end{array}$ & $\begin{array}{c}P \text {-value } \\
(\mathrm{A}-\mathrm{C})\end{array}$ & $\begin{array}{c}P \text {-value } \\
(\mathrm{B}-\mathrm{C})\end{array}$ \\
\hline Complete success & 30 & 7 & 4 & 0.091 & 0.172 & 0.018 \\
\hline Partial success & 26 & 1 & 2 & 0.021 & 0.018 & 0.859 \\
\hline Recurrence & 24 & 3 & 12 & 0.849 & 0.190 & 0.024 \\
\hline
\end{tabular}

Table V. Comparison between pleurodesis methods used according to group

\begin{tabular}{|lccc|}
\hline Variable & Group I & Group II & \multirow{2}{*}{$P$-value } \\
\cline { 2 - 3 } & Tube thoracostomy $(n=21)$ & Tube thoracostomy $(n=80)$ & 0.657 \\
\hline Complete success & 9 & 30 & 0.942 \\
\hline Partial success & 7 & 26 & 0.560 \\
\hline Recurrence & 5 & 24 & 0.714 \\
\hline & Thoracoscopy $(n=9)$ & Thoracoscopy $(n=11)$ & 0.285 \\
\hline Complete success & 5 & 7 & 0.591 \\
\hline Partial success & 3 & 1 & \\
\hline Recurrence & 1 & 3 & 0.001 \\
\hline & PleurX catheter $(n=49)$ & 4 & 0.001 \\
\hline Complete success & 3 & 2 & 0.001 \\
\hline Partial success & 11 & 12 & PleurX catheter $(n=18)$ \\
\hline Recurrence & 5 & 4 & \\
\hline
\end{tabular}

Table VI. Multiple logistic regression results

\begin{tabular}{|c|c|c|}
\hline Variables & $\mathrm{HR}(95 \% \mathrm{Cl})$ & $P$-value \\
\hline Age & $1.0185(0.6819-1.550)$ & 0.1016 \\
\hline Gender & $2.1722(0.02469-23.2789)$ & 0.6316 \\
\hline Groups (I and II) & $5.0958(0.0165-24.1224)$ & 0.0200 \\
\hline $\begin{array}{l}\text { Pathology } \\
\text { causing MPE }\end{array}$ & $9.4095(0.0742-1124.24)$ & 0.7115 \\
\hline $\begin{array}{l}\text { Method of } \\
\text { pleurodesis }\end{array}$ & $3.2584(1.9249-1421.76)$ & 0.3699 \\
\hline Cancer stage & $2.7807(0.5408-23.85)$ & 0.5121 \\
\hline $\begin{array}{l}\text { Accompanying } \\
\text { disease }\end{array}$ & $2.8626(0.8687-75.88)$ & 0.0328 \\
\hline $\begin{array}{l}\text { Amount of } \\
\text { pleural fluid }\end{array}$ & $0.9499(0.8540-1.0834)$ & 0.0658 \\
\hline \multicolumn{3}{|c|}{ Model fitting information } \\
\hline$R^{2}$ (Nagelkerke) & 0.8661 & \\
\hline & Log likelihood & Ratio test \\
\hline Intercept only & 397.01 & Sig. \\
\hline
\end{tabular}

no effect with regard to preventing the re-accumulation of pleural fluid.

In addition, the significance levels of the other parameters, method of pleurodesis, gender, pathology-causing MPE, and cancer stage, were significantly higher when the effects on success were examined together for each group. According to these results, when the aforementioned data were jointly evaluated for both groups, there was no meaningful effect on success. The value obtained when assessing the success of preventing the re-accumulation of pleural fluid was slightly greater than the significance level of 0.05 (Table VI).

Following this assessment, a multiple logistic regression model was established to examine the relationship between patient characteristics and pleurodesis separately for each group. Results of multiple logistic regression analysis for group I and group II are presented in Table VII.

When the fit data of the model for multiple regression is examined, the model is found to be a good fit for both groups (group I: $p=0.00012$; group I: $p=0.00015)$. $R^{2}$, calculated according 
Table VII. Multiple logistic regression results

\begin{tabular}{|c|c|c|c|c|}
\hline \multirow[t]{2}{*}{ Variables } & \multicolumn{2}{|l|}{ Group I } & \multicolumn{2}{|l|}{ Group II } \\
\hline & HR $(95 \% \mathrm{Cl})$ & $P$-value & HR $(95 \% \mathrm{Cl})$ & $P$-value \\
\hline Age & $1.324(0.766-2.289)$ & 0.0750 & $0.797(0.621-1.023)$ & 0.121 \\
\hline Gender & $2.32(0.393-13.608)$ & 0.8490 & $2.065(0.141-30.288)$ & 0.474 \\
\hline Pathology - causing MPE & $1.038(0.00135-80.976)$ & 0.9510 & $15.477(0.127-1880.367)$ & 0.538 \\
\hline Method of pleurodesis & $4.912(0.0007-3312.92)$ & 0.0910 & $2.060(0.083-51.088)$ & 0.572 \\
\hline Cancer stage & $5.9523(4.4842-7.900)$ & 0.0030 & $0.482(0.07-35.408)$ & 0.881 \\
\hline Accompanying disease & $2.502(1.276-8.873)$ & 0.0090 & $3.124(0.008-124.45)$ & 0.05 \\
\hline The amount of pleural fluid & $0.90(0.722-1.122)$ & 0.1400 & $0.986(0.975-0.997)$ & 0.012 \\
\hline \multicolumn{5}{|c|}{ Model fitting information } \\
\hline \multirow[t]{2}{*}{$R^{2}$ (Nagelkerke) } & 0.785 & 0.925 & & \\
\hline & Log likelihood & Ratio test & Log likelihood & Ratio test \\
\hline Intercept only & 1.489 .918 & Sig. & 237.14 & Sig. \\
\hline Final & 624.562 & 0.00012 & 50.39 & 0.00015 \\
\hline
\end{tabular}

Table VIII. Survival time results

\begin{tabular}{|lcccc|}
\hline Groups & Estimate & Std. error & Lower bound & Upper bound \\
\hline I & 168.000 & 2.710 & 162.688 & 173.312 \\
\hline II & 91.000 & 2.454 & 86.190 & 95.810 \\
\hline Overall & 149.000 & 17.464 & 114.770 & 183.230 \\
\hline
\end{tabular}

to the pseudo $r^{2}$ values model, summarizes the proportion of variance in the dependent variable associated with the predictor (independent) variables. In the first model, the Nagelkerke [4] $r^{2}$ value was 0.785 , while that of the second model was 0.925 , indicating that the second model has greater explanatory power.

Examining the regression data for group I, the presence of cancer and comorbid diseases (heart failure, diabetes, kidney failure, etc.) were observed to have an effect on success in preventing recurrence of pleural effusion following pleurodesis. The $p$-value for age of patients was found to be slightly higher than the significance level of 0.05. However, the significance level for method of pleurodesis was 0.0910 , while that for the amount of pleural fluid was 0.14 . Gender and cancer pathology (pathologies causing MPE) were not significantly associated with success in preventing recurrence of pleural effusion following pleurodesis in group I patients.

The results for group II showed that success in preventing recurrence of pleural effusion following pleurodesis was associated with comorbid disease and amount of pleural fluid, with $p$-values of 0.05 and 0.012 , respectively. The $p$-value for age of patients in group II was not significant $(p=0.121)$. Also, gender, pathologies causing MPE, method of pleurodesis, and cancer stage were not significantly associated with success in preventing recurrence of pleural effusion following pleurodesis.

\section{Cumulative probability of survival}

Comparison of groups: In this section, the effect of each group on survival time is first examined. Survival test results and statistical result are given in Tables VIII and IX.

When only the effect of group on survival time was examined, the difference between groups I and group II was statistically significant.

The level of significance was below $5 \%$ for all three methods (Montel-Cox, generalized Wilcoxon, Tarone-Ware). Regarding survival times results, the shortest in group I was 162.688 days and the longest was 173.312, with a median of 168 days. In group II, the shortest survival time

Table IX. Survival times test statistics

\begin{tabular}{|lccc|}
\hline Variable & $\chi^{2}$ & $\mathrm{~d} f$ & Sig. \\
\hline Log rank (Mantel-Cox) & 48.462 & 1 & $<0.001$ \\
\hline $\begin{array}{l}\text { Breslow } \\
\text { (generalized Wilcoxon) }\end{array}$ & 54.595 & 1 & $<0.001$ \\
\hline Tarone-Ware & 55.168 & 1 & $<0.001$ \\
\hline
\end{tabular}




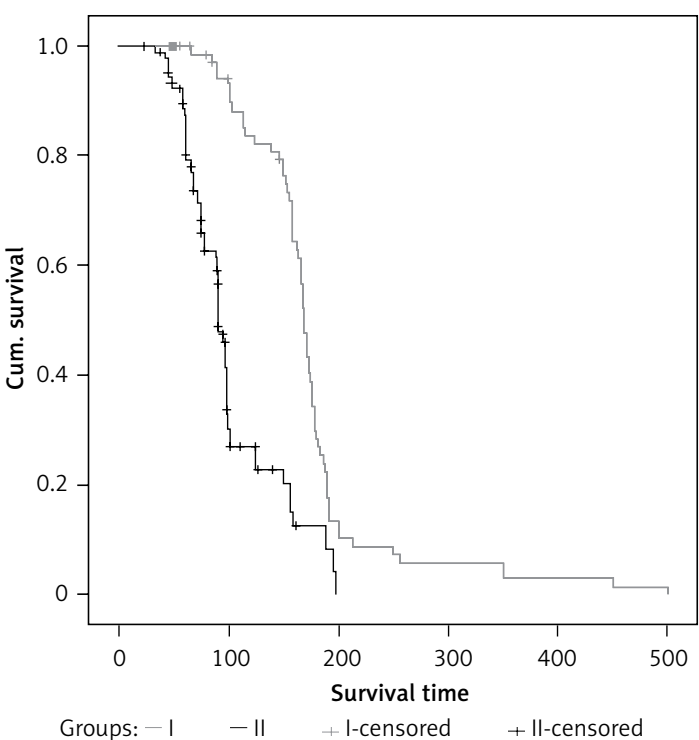

Figure 1. Cumulative survival of groups

was 86.190 , the longest was 95.810 , and the median was 91 days. The mean survival time for all patients was 149 days.
According to the test results, there was a significant difference in survival time between group I and group II, with group I exhibiting longer average survival time.

In Figure 1 the difference between the groups is clearly visible. When evaluated according to time periods, survival time differed between groups for all time periods.

Effect of patient characteristics on survival time, separately for each group: in this section, the effects of patient characteristics on survival time were evaluated separately for the two groups.

Patient survival times were calculated using the prediction model based on the Kaplan-Meier survival method. The results of the survival estimates for groups I and II are given in Table X. The graphs of survival functions based on estimates made using the Kaplan-Meier method are shown in Figures 2-6.

In calculating survival time, pathologies causing MPE (type of cancer) was significant for group I, with an estimated average survival time of 196.73 days. The mean survival time for group II was 121.18 days, and as with group I, pathologies

Table X. Test of equality of survival distributions

\begin{tabular}{|lcccc|}
\hline Variable & \multicolumn{2}{c}{ Group I } & \multicolumn{2}{c|}{ Group II } \\
\cline { 2 - 5 } & $\chi^{2}$ & Sig. & $\chi^{2}$ & Sig. \\
\hline Gender & 1.298 & 0.255 & 1.071 & 0.301 \\
\hline Pathology causing MPE & 12.263 & 0.031 & 23.481 & 0.009 \\
\hline Method of pleurodesis & 0.229 & 0.892 & 0.699 & 0.716 \\
\hline Cancer stage & 4.067 & 0.254 & 2.391 & 0.303 \\
\hline Accompanying disease & 0.025 & 0.875 & 1.171 & 0.279 \\
\hline Estimate of survival time & \multicolumn{2}{c}{196.73 days } & \multicolumn{2}{c|}{121.18 days } \\
\hline
\end{tabular}

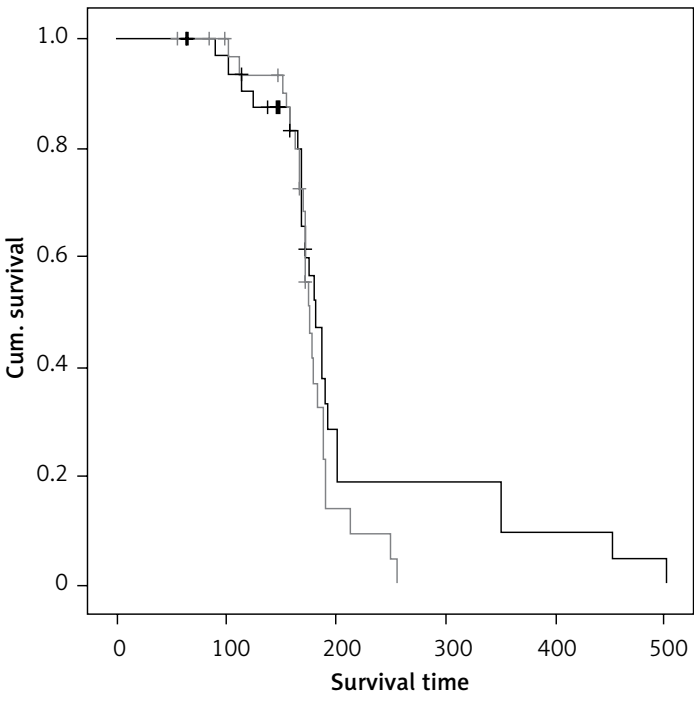

- Male - Female

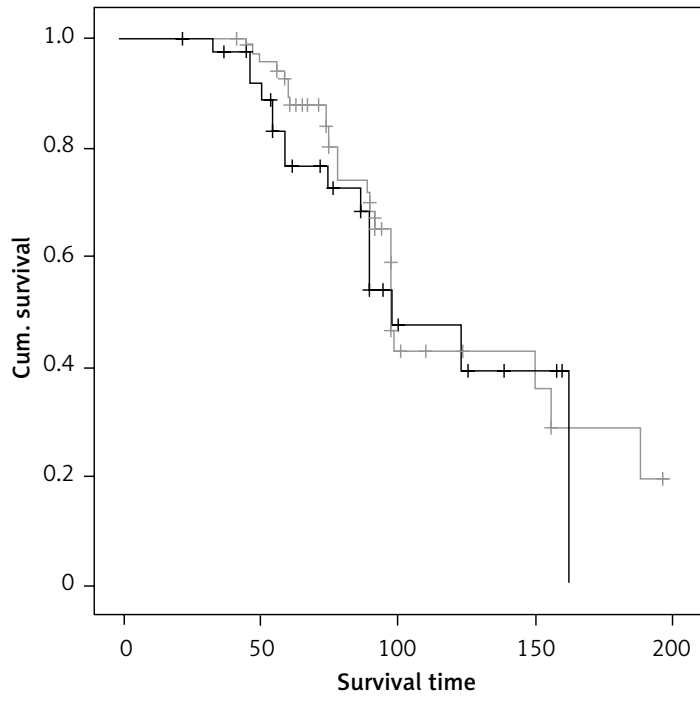

Figure 2. Cumulative survival by gender 

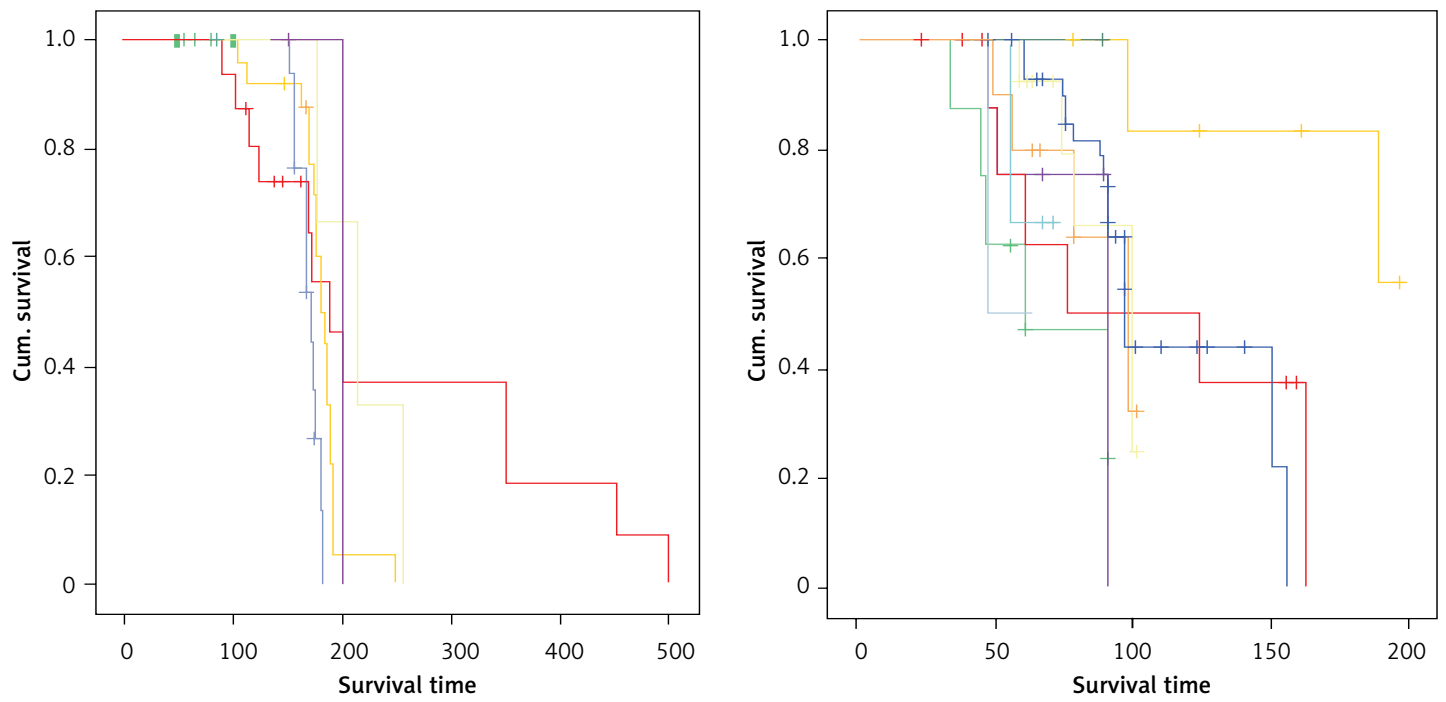

$$
\begin{aligned}
& \text { Pathologies causing MPE: - NSCLC - SCLC - Lymphoma - Ovarian cancer metastasy - Stomach cancer } \\
& \text { - Breast cancer - Larynx cancer - Prostate cancer - Pancreatic cancer } \\
& \text { - Malignant fibrous histiocytoma - Esophageal cancer }
\end{aligned}
$$

Figure 3. Cumulative survival of pathologies causing MPE
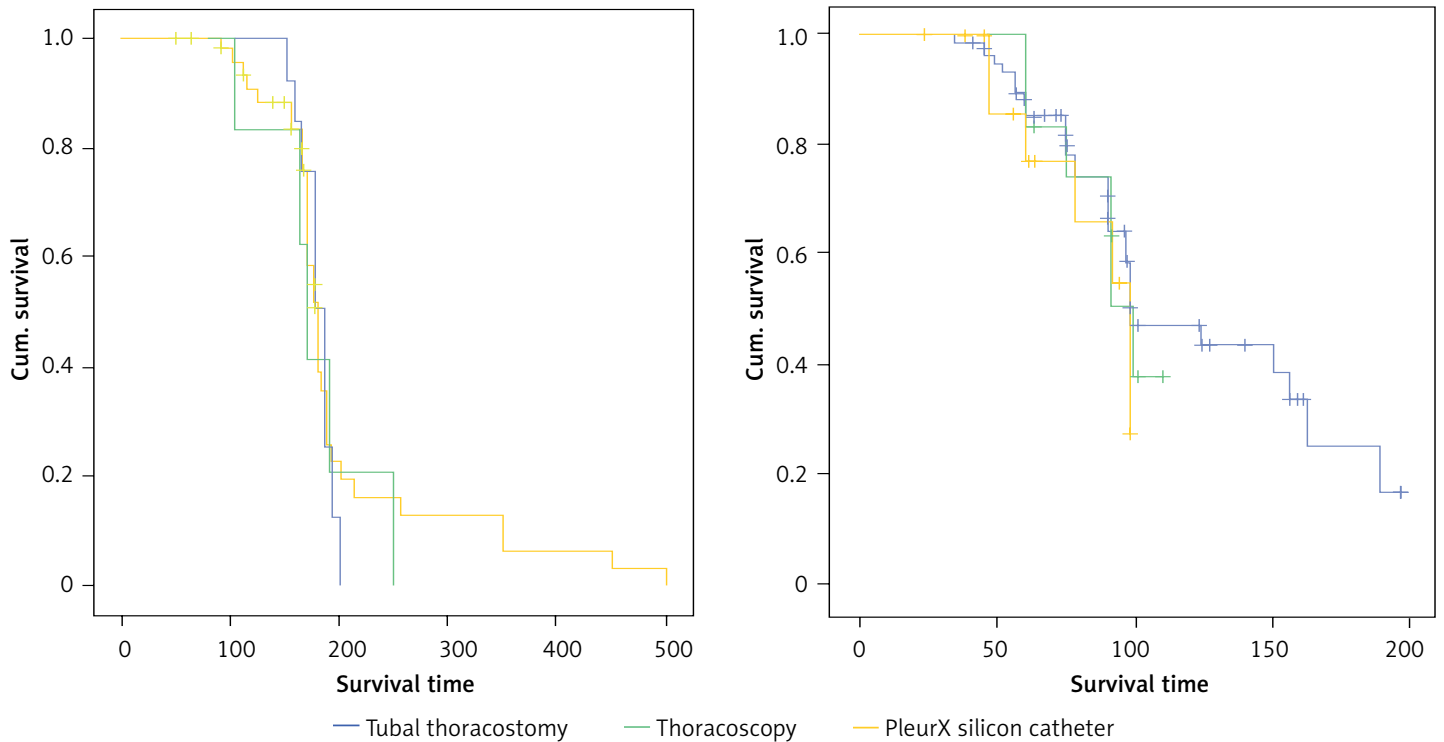

Figure 4. Cumulative survival of method of pleurodesis

causing MPE (type of cancer) had a major effect in predicting survival time.

In Figure 3, which shows the survival times for various types of cancer, there is no significant difference between the types of cancer in group I, except for breast cancer. In the group II data, prostate cancer behaves differently from the other types of cancer, whereas the other types of cancer have similar effects on survival time. These two graphs clearly show that the type of cancer has a significant effect on survival time.

In Figure 4, which shows the effect of treatment method, the PleurX catheter method has a different effect on survival time for group I compared to the other two methods. However, there was no significant difference in effect between the methods during the initial and middle periods for group II, while thoracoscopy was observed to have a significant effect in the final period.

The effect of cancer stage on survival time is shown in Figure 5. Examining the data for group I, the first three stages of cancer were found to have similar effects on survival time, whereas stage 4 had a significantly different impact on survival time. In group II, the majority of cases were stage 4; thus no significant difference could be observed due to insufficient patient numbers for the other cancer stages. 


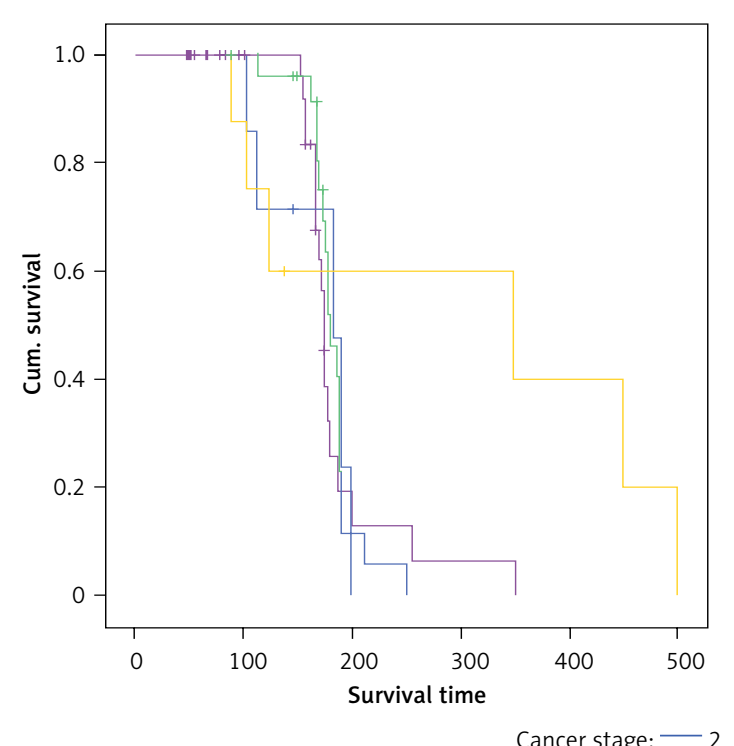

Figure 5. Cumulative survival of cancer stage

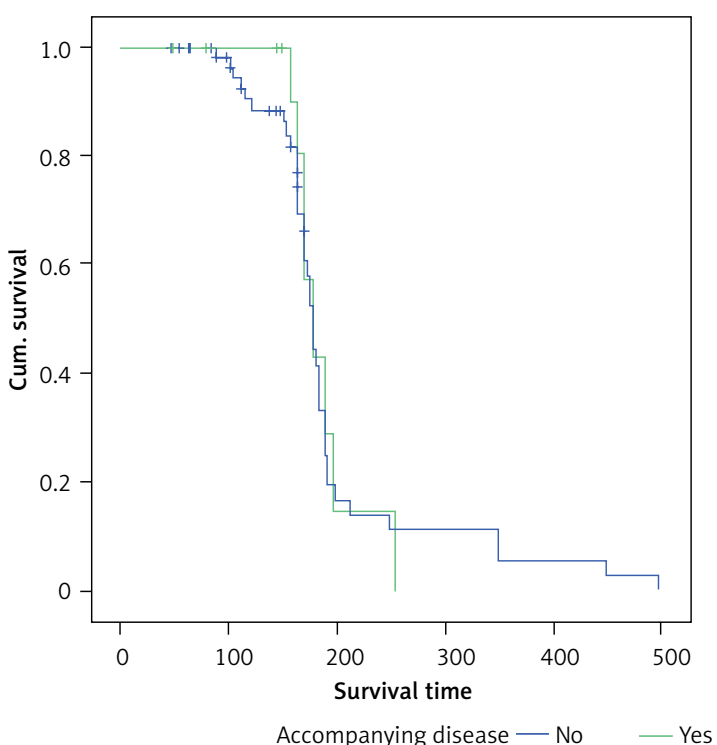

Figure 6. Cumulative survival of accompanying disease

The effects of comorbid diseases in groups and II on patient survival time were investigated (Figure 6). While no significant difference in survival time was observed for either group during the first and middle periods, the presence of other diseases did have a significant effect on survival time in the final period.

\section{Discussion}

The effective control of MPE is of paramount importance in the treatment of patients with disseminated cancer, as effusion can result in dyspnea, decreased exercise tolerance, and increased mortality.

Carcinoma in any organ has the ability to metastasize to pleura. However, it is expected that
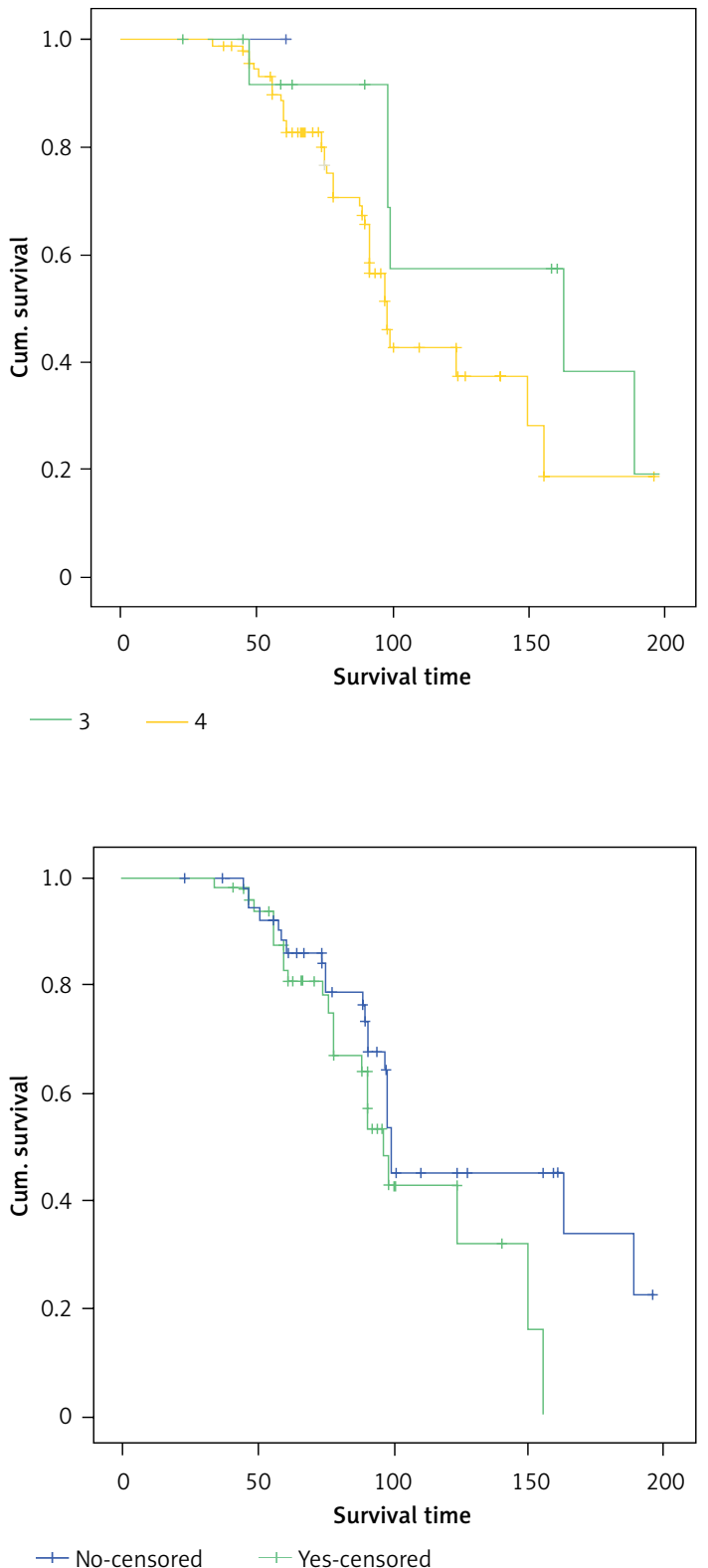

lung carcinomas are most likely to reach the pleura and cause pleural effusion due both to their adjacency and their involvement in the circulatory system. In fact, in all large and reliable series studies, the most frequent cause of MPE is lung cancer, followed by breast cancer [3].

In our study, the most frequent pathology causing MPE in both groups was determined to be lung cancer (84/188; 44.68\%), in accordance with the literature. This was followed by lymphoma (34/188; 18.08\%) and breast cancer (27/188; $14.36 \%)$.

A small amount of pleural effusion does not cause symptoms; $15 \%$ of pleural effusions do not produce symptoms [5]. When the amount of pleural effusion increases, symptoms begin to appear. 
The most frequently observed symptoms are pleuritic pain, dry cough, and breathing difficulties [1].

In this study, group I patients had low levels of pleural fluid and were in the asymptomatic phase, while group II patients had excessive amounts of pleural effusion fluid and exhibited such symptoms as pleuritic pain, dry cough, and respiratory difficulties.

In patients with pleural effusion in which diagnosis cannot be confirmed via cytology or biopsy, findings which suggest malignancy include a symptomatic period lasting more than one month, absence of fever, sanguineous pleural flu$\mathrm{id}$, and CT results pointing to malignancy (pulmonary or pleural malignancy such as pleural mass, lymphadenopathy) [6].

In our series, while malignant cells were detected in $53.73 \%$ of cases by pleural fluid cytology, closed pleura biopsy, and thoracoscopic biopsy, in $46.27 \%$ of cases, malignant cells could not be detected in pleural fluid or pleural biopsy, despite the presence of a primary tumor. In these patients the diagnostic criteria for MPE suggested in the literature were applied.

In confirming pleural effusion, the first step is the posterior-anterior graph (PA) lung graph. Thorax CT may be useful in MPEs. Computed tomography provides information regarding whether MPE is localized, about the condition of the primary disease, and the anatomy of other organs in the thorax. In particular, PET-CT can be used to confirm metastatic findings in other organs $[1,6]$.

Pleural effusion for all cases in the present study was evaluated using direct radiography. For group I, the PA and standard lateral lung graph confirmed blunting in the costophrenic sinuses. In group II patients, following obtundation of the costophrenic sinuses and obliteration of the contour of the diaphragm, indications of a concave homogeneous density and pushing against the mediastinum were detected. Computed tomography was used to confirm parenchymal or mediastinal lesions accompanying pleural fluid.

For MPE, the aim of treatment is minimal morbidity within the limited lifespan of patients by using the least invasive procedures, and easing labored breathing by removing fluid from the pleural cavity. Every $1,000 \mathrm{ml}$ of fluid drained leads to an increase of $400 \mathrm{ml}$, on average, in the total lung capacity [7].

In order to remove fluid from the pleural cavity, thoracentesis, durable narrow catheters, tube thoracostomy or video-assisted thoracoscopic surgery (VATS) can be employed. However, drainage of the pleural cavity is not sufficient in palliative care. Fluid usually accumulates again within one month in $90 \%$ of patients [8]. For this reason, the goal for MPE cases should be to inhibit new accu- mulation of pleural fluid. The procedure administered to achieve this goal is pleurodesis.

Pleurodesis is the iatrogenic closure of the pleural cavity by means of inducing pleural fibrosis, thus inhibiting the collection of fluid. Either a chemical agent can be used or the surgical techniques of abrasion or pleurectomy can be employed; in either case, the mechanism is the infliction of damage to the pleura. However, if much damage is incurred, inflammation will also occur; the formation of pleural scar tissue, i.e., pleurodesis, will be successful to that extent as a result [9].

In preventing the re-accumulation of fluid, pleurectomy performed via thoracotomy and decortication ensure effective pleurodesis. However, with these procedures, mortality exceeds $10 \%$, and there is, in particular, morbidity in the form of persistent air leak [10].

In chemical pleurodesis, the ideal sclerosing agent should have a high level of efficacy, be inexpensive, not cause serious side effects, and should be able to be easily administered [11]. As talc possesses these characteristics, it is used quite frequently.

Talc occurs in nature in the form of layers of magnesium silicate $\left(\mathrm{Mg}_{3} \mathrm{Si}_{4} \mathrm{O}_{10}(\mathrm{OH})_{2}\right)$ and is commonly found together with asbestos. For intrapleural use, trade preparations exist which have traditionally been separated from asbestos fibers [12].

Among chemical pleurodesis materials, talc has been shown to be the most effective in preventing recurrence of MPE, with most studies reporting 75$95 \%$ success rates [13]. In the present study, talc was the preferred choice for the sclerosing agent.

In the literature, complications such as pain, fever, dyspnea, acute pneumonia, and respiratory insufficiency have been reported in patients who have undergone pleurodesis [13]. In our series, doses of 2.5-4 g of talc were used, and in 15 cases $(5 / 188 ; 2.65 \%)$ atelectasis occurred (Table II). In no cases were potentially fatal complications, such as acute respiratory distress syndrome (ARDS) or respiratory insufficiency, observed.

For successful pleurodesis, after the complete emptying of the intrapleural cavity, the key factor is the full expansion of the lungs, and ensuring full physical contact between the visceral and parietal pleura. Failure of pleurodesis is caused by incomplete drainage of the pleural cavity, unequal distribution of the sclerosing agent, or trapped lung [14].

In this study, the complete success and recurrence rates of the group I patients, in which pleurodesis was performed when the volume of pleural fluid was still low, were statistically significantly higher than those of group II patients, who had excessive effusion (Table II). In cases where the amount of effusion was low, ensuring complete physical contact between the visceral and parietal pleura resulted in an increased chance of 
success. In 2007, Steger et al. reported that early pleurodesis was more successful in the prevention of recurrence, which supports our prediction [15].

In group I patients, who underwent pleurodesis when the volume of pleural fluid was low, no differences in success rates and prevention of recurrence between the methods of pleurodesis employed (tube thoracostomy, thoracoscopy, and PleurX catheter) were detected. These results indicate that in those who undergo pleurodesis at an early phase, fundamental success is ensured not by the technique employed but rather is due to the low volume of fluid and full contact between the pleural membranes (Table III).

However, in group II cases with excessive effusion, the technique employed was of the utmost importance in determining success and preventing recurrence. For complete success, thoracoscopy was found to be more successful than the PleurX catheter, while tube thoracostomy was more successful than both thoracoscopy and the PleurX catheter methods for partial success. Thoracoscopy was determined to be superior to the PleurX catheter in preventing recurrence (Table IV).

Although there are published reports that talc powder administered with thoracoscopy had lower recurrence rates compared to talc powder administered by tube thoracostomy, with respect to success, no study has found a significant difference between the two methods $[14,16]$. The present study did not establish the superiority of the thoracoscopic method compared to tube thoracostomy.

Traditionally, large tubes for pleurodesis are recommended. Some studies have suggested that there is no difference in efficacy with regard to narrow-diameter tubes as opposed to wide-diameter tubes [17]. In accordance with the literature, this study found no statistically significant difference between the two techniques in terms of complete success and prevention of recurrence. However, thoracoscopic application was determined to be clearly superior to the narrow catheter method in complete success rates and prevention of recurrence (Table IV).

In our study, the effects of patient characteristics and patient group on success in preventing the re-accumulation of pleural fluid were examined, together with the above statistical studies. The different groups and the presence of disease accompanying the cancer (comorbidity) were observed to have effects on success rates, whereas other parameters had no effect (Table VI).

Patient characteristics for each group were then examined separately with respect to their success in preventing re-accumulation of pleural fluid following pleurodesis (Table $\mathrm{X}$ ).

In group I cases, cancer stage and the presence of comorbid diseases (heart failure, diabetes, kidney failure, etc.) were observed to have an effect on success in preventing recurrence of pleural effusion following pleurodesis. For group II cases, comorbidity and the amount of pleural fluid were determined to be related to success rates.

Following a diagnosis of MPE, although the mean survival rate varies depending on the organ where the primary tumor originated, the histological type, and the stage of the disease, an estimate of 3-12 months can generally be given. In a number of studies, the type of cancer, cell type, tumor stage, pleural fluid characteristics, pleural fluid biomarkers, pleural tumor involvement, and overall performance status of the patient were found to affect mean survival $[18,19]$.

Some studies have concluded that the prognosis of patients with pleural effusions who underwent talc pleurodesis was independent of age, gender, type of malignancy, and pleural fluid volume; however, prognosis was closely related to the response of the underlying systemic tumor to treatment. For example, patients with chemotherapy-responsive lymphoma or breast cancer were more likely to survive longer than patients with effusions caused by non-small cell lung cancer [20-22]. Similarly, in some studies, the shortest survival time was found in malignant effusions secondary to lung cancer, while the longest was observed in ovarian cancer [23].

According to the results of the statistical analyses of the present study, there was a significant difference in terms of survival time between group I and group II, with group I having longer survival times (Table IX, Figure 1).

Also, pathologies causing MPE (type of cancer) had an important effect in the prediction of survival time for group I and group II cases. In addition, when the effect of cancer stage on survival time was examined in group I cases, as the cancer stage progressed, its effect on survival time became more evident. As most patients in group II were already at stage 4 , no effect on survival time due to cancer stage was detected. The presence of comorbid disease in both group I and group II cases was determined to have an effect on survival time, especially in the final period. All of these findings are consistent with the literature [18-23].

In conclusion, in the treatment of MPE, the primary goal is to alleviate symptoms in patients, improve the quality of life, and prevent recurrence of pleural effusion. In this study, pleurodesis was found to have a low rate of success and high probability of recurrence of effusion in late phase cases in which the quantity of pleural effusion had increased. By contrast, in cases with low amounts of pleural effusion, due to improved contact of the parietal and visceral pleural membranes, pleurodesis performed at an early phase was more successful and recurrence was clearly decreased. Based on these findings, we hypothesize that in 
MPE patients, clinicians may consider pleurodesis as an alternative in the early stage when there is minimal buildup of pleural fluid.

\section{Conflict of interest}

The authors declare no conflict of interest.

\section{References}

1. Marel M, Fila L, Červená M. The differential diagnosis of pleural effusions. Vnitr Lek Fall 2016; 62: 598-604.

2. Psallidas I, Kalomenidis I, Porcel JM, et al. Malignant pleural effusion: from bench to bedside. Eur Respir Rev 2016; 25: 189-98.

3. Dixit R, Agarwal KC, Gokhroo A, et al. Diagnosis and management options in malignant pleural effusions. Lung India 2017; 34: 160-6.

4. Nagelkerke NJD. A note on the general definition of the coefficient of determination. Biometrika 1991; 78: 691-2.

5. Clive, $A$, Jones, $H$, Bhatnagar $R$, et al. Interventions for the management of malignant pleural effusions: a network meta-analysis. Cochrane Database Syst Rev 2016; 5: CD010529.

6. Poyraz N, Kalkan H, Odev K, et al. Imaging of pleural diseases: evaluation of imaging methods based on chest radiography. Tuberk Toraks 2017; 65: 41-55.

7. Lee YCG, Light RW. Pleural effusion: overview. In: Encyclopedia of Respiratory Diseases. $4^{\text {th }}$ ed. Laurent GJ, Shapiro S (eds). Elsevier, Oxford 2006; 353-8.

8. Davies HE, Lee YC. Management of malignant pleural effusions: questions that need answers. Curr Opin Pulm Med 2013; 19: 374-9.

9. Shaw P, Agarwal R. Pleurodesis for malignant pleural effusions. Cochrane Database Syst Rev 2004; 1: CD002916.

10. Ferreiro L, Suárez-Antelo J, Valdés L. Pleural procedures in the management of malignant effusions. Ann Thorac Med 2017; 12: 3-10.

11. Roberts ME, Neville E, Berrisford RG, et al. BTS Pleural Disease Guideline Group. Management of a malignant pleural effusion: British Thoracic Society Pleural Disease Guideline 2010. Thorax 2010; 65: 32-40.

12. Santos PS, Marques MA, Cruz C, et al. Predictors of talc slurry pleurodesis success in patients with malignant pleural effusions. Rev Port Pneumol 2017; 23: 216-20.

13. Agarwal R, Paul AS, Aggarwal AN, et al. A randomized controlled trial of the efficacy of cosmetic talc compared with iodopovidone for chemical pleurodesis. Respirology 2011; 16: 1064-9.

14. Rodriguez-Panadero F, Montes-Worboys A. Mechanisms of pleurodesis. Respiration 2012; 83: 91-8.

15. Steger $V$, Mika $U$, Toomes $H$, et al. Who gains most? A 10-year experience with 611 thoracoscopic talc pleurodeses. Ann Thorac Surg 2007; 83: 1940-5.

16. Hunt BM, Farivar AS, Vallières E, et al. Thoracoscopic talc versus tunneled pleural catheters for palliation of malignant pleural effusions. Ann Thorac Surg 2012; 94: 1053-7.

17. Fysh ET, Waterer GW, Kendall PA, et al. Indwelling pleural catheters reduce inpatient days over pleurodesis for malignant pleural effusion. Chest 2012; 142: 394-400.

18. Bernard A, de Dompsure RB, Hagry O, et al. Early and late mortality after pleurodesis for malignant pleural effusion. Ann Thorac Surg 2002; 74: 213-7.

19. Rajwa P, Życzkowski M, Paradysz A, et al. Novel hematological biomarkers predict survival in renal cell carci- noma patients treated with nephrectomy. Arch Med Sci 2017; DOI: https://doi.org/10.5114/aoms.2017.70250.

20. Spych M, Gottwald L, Klonowicz M, et al. The analysis of prognostic factors affecting post-radiation acute reaction after conformal radiotherapy for non-small cell lung cancer. Arch Med Sci 2010; 5: 756-3.

21. Law MF, Chan HN, Leung C, et al. Marginal zone B-cell lymphoma mimicking extramedullary plasmacytoma and the clinical outcome after treatment. Arch Med Sci 2017; 13: 698-701.

22. Szychta P, Westfal B, Maciejczyk R, et al. Intraoperative diagnosis of sentinel lymph node metastases in breast cancer treatment with one-step nucleic acid amplification assay (OSNA). Arch Med Sci 2016; 12: 1239-46.

23. Clive AO, Kahan BC, Hooper CE, et al. Predicting survival in malignant pleural effusion: development and validation of the LENT prognostic score. Thorax 2014; 69: 1098-104. 